\title{
Fabrication of Ti/Ir-Ru electrode by spin coating method for electrochemical removal of copper
}

\author{
Joohyun Kim, Sungjun Bae ${ }^{\dagger}$ \\ Department of Civil and Environmental Engineering, Konkuk University, Seoul 05029, Republic of Korea
}

\begin{abstract}
Recovery of valuable metals in the industrial wastewater and sludge has attracted an attention owing to limited metallic resources in the earth. In this study, we firstly fabricated Ti/Ir-Ru electrodes by spin coating technique for effective recovery of Cu in electrowinning process. Two different Ti/Ir-Ru electrodes were fabricated using 100 and $500 \mathrm{mM}$ of precursors (i.e., Ir-Ru). SEM-EDX and AFM revealed that Ir and $\mathrm{Ru}$ were homogenously distributed on the surface of Ti plate by the spin coating, in particular the electrode prepared by $500 \mathrm{mM}$ showed distinct boundary line between Ir-Ru layer and Ti substrate. XRD, XPS, and cyclic voltammetry also revealed that characteristics of $\mathrm{IrO}_{2}$, $\mathrm{RuO}_{2}$, and $\mathrm{TiO}_{2}$ and its electrocatalytic property increased as the concentration of coating precursor increased. Finally, we carried out Cu recovery experiments using two Ti/Ir-Ru as anodes in electrowinning process, showing that both anodes showed a complete removal of $\mathrm{Cu}(1 \mathrm{and}$ $10 \mathrm{~g} / \mathrm{L}$ ) within $6 \mathrm{~h}$ reaction, but much higher kinetic rate constant was obtained by the anode prepared by $500 \mathrm{mM}$. The findings in this study can provide a fundamental knowledge for surface characteristics of Ti/Ir-Ru electrode prepared by spin coating method and its potential feasibility for effective electrowinning process.
\end{abstract}

Keywords: $\mathrm{Cu}$ removal, Electrowinning, Spin coating, Surface characterization, Ti/Ir-Ru anode

\section{Introduction}

Generation of industrial wastewater and sludge containing various metals has continuously increased owing to a dramatic increase of metal usage during the industrialization and urbanization. In particular, metals such as copper, nickel, zinc, lead, cadmium, and chromium are highly contained in the industrial wastewater produced from electroplating, mining, smelting, battery and paint manufacturing, and printing industries $[1,2]$. Because these highly concentrated metals can induce severe environmental pollutions and negatively influence human health causing carcinogenesis and some diseases when they are discharged to natural environments without appropriate treatment [3, 4].

Precipitation is one of most commonly used methods for removal of metals in industrial wastewater and sludge by forming metal hydroxides with $\mathrm{CaOH}_{2}$ or $\mathrm{NaOH}$. However, secondary treatment processes are usually required to remove metals in the precipitated metal sludges, resulting in increase of operation cost largely [5]. Over the last few decades, the efforts on recovery of valuable metals in the industrial wastewater and sludge were to obtain metallic resources and reduce the amount of waste disposal. Several methods such as solvent extraction, ion exchange, membrane technology, ferrite process, and extraction separation have been developed to effectively recover metals from wastewater and toxic sludge $[5,6]$.

Electrowinning, a method for electrodeposition of metals onto the cathode, has been applied for metal recovery normally in acidic wastewater. Due to a relatively low cost, lead alloys are commonly used as an economic anode for electrowinning process [6]. However, the lead-based anodes revealed some drawbacks such as high energy consumption efficiency and low corrosion resistance [7]. In order to solve these problems, researchers have investigated various metals for development of effective anode substrate and commonly selected a titanium (Ti) substrate due to its corrosion resistance [8]. Recently, tantalum $\left(\mathrm{Ta}_{2} \mathrm{O}_{5}\right)$, tin $\left(\mathrm{SnO}_{2}\right)$, iridium $\left(\mathrm{IrO}_{2}\right)$, ruthenium $\left(\mathrm{RuO}_{2}\right)$ oxides and their combinations have been used for enhancement of electrocatalytic activity, stability, and energy efficiency of anodes [9]. Among the metal oxides, $\mathrm{RuO}_{2}$ showed the highest electrocatalytic activity with a relatively short life time [10], while $\mathrm{IrO}_{2}$ has slightly lower
This is an Open Access article distributed under the terms of the Creative Commons Attribution Non-Commercial License (http://creativecommons.org/licenses/by-nc/3.0/) which permits unrestricted non-commercial use, distribution, and reproduction in any medium, provided the original work is properly cited.

Copyright (C) 2019 Korean Society of Environmental Engineers
Received July 10, 2018 Accepted December 31, 2018

${ }^{\dagger}$ Corresponding author

Email: bsj1003@konkuk.ac.kr

Tel: +82-42-450-3904

ORCID: 0000-0003-1666-5982 
electrocatalytic activity and longer lifetime (almost 20 times) than that of $\mathrm{RuO}_{2}$ with an excellent stability in acidic media [11]. Therefore, a combination of $\mathrm{IrO}_{2}$ and $\mathrm{RuO}_{2}$ has been used for development of efficient anodes working on electrowinning process [12].

During fabrication of oxide coated electrode, a coating method of $\mathrm{Ir}$ and $\mathrm{Ru}$ oxides on Ti substrate can significantly influence the efficiency of electrowinning process because electrical properties of electrode are totally dependent on coating surface. Compared to other coating methods (e.g., brush-, spray-, dip-coating), spin coating technique using centrifugal force for spreading precursor solution on the surface of substrate could be an excellent alternative because the oxide films may form more uniformly and easier to control the surface layer by applying different precursor concentration, rotation speed, and time [13]. The development of Ti/Ir electrode by the spin coating has been reported, but researchers mainly focused on the kinetics study of formic acid oxidation showing that only the effect of $\mathrm{IrO}_{2}$ content and organic concentration (i.e., formic acid) on the oxidation efficiency of formic acid [14]. However, details for surface characteristics of Ti/Ir electrode characterized by physical-chemical surface analysis was not provided in the previous study. Therefore, a limited knowledge has been provided for development of Ti/Ir-Ru electrode by the spin coating technique to date, thus its surface characteristics and application to electrowinning process have not reported well.

In this study, we firstly used the spin coating technique to develop and characterize the Ti/Ir-Ru electrodes prepared by different concentrations of precursor solution. In order to characterize the surface of Ti/Ir-Ru, different surface analysis was carried out by using field emission scanning electron microscopy with energy dispersive X-ray spectroscopy (FESEM-EDX), atomic force microscopy (AFM), X-ray diffraction (XRD), and X-ray photoelectron spectroscopy (XPS). Cyclic voltammetry was also used to investigate electrochemical characterization of $\mathrm{Ti} / \mathrm{Ir}-\mathrm{Ru}$ electrodes. Finally, we performed the electrowinning of synthetic wastewater containing $\mathrm{Cu}$ in $0.5 \mathrm{M} \mathrm{H}_{2} \mathrm{SO}_{4}$ to highlight the potential feasibility of $\mathrm{Ti} / \mathrm{Ir}-\mathrm{Ru}$ as an effective anode for metal recovery by electrowinning process.

\section{Experimental}

\subsection{Development of $\mathrm{Ti} / \mathrm{Ir}-\mathrm{Ru}$ Anodes}

$\mathrm{Ti} / \mathrm{Ir}-\mathrm{Ru}$ anodes were prepared by a thermal decomposition of iridium and ruthenium chloride precursor mixtures. Ti substrates $\left(10 \times 10 \times 0.04 \mathrm{~cm}^{3}\right)$ were scrubbed by silicon carbide (SIC) paper to improve roughness of the surface, and washed with deionized water (DIW, 18.2 M $\Omega \mathrm{cm}$, ELGA PURELAB Classic system). Then, the Ti substrates were chemically etched in $10 \%$ boiling oxalic acid for $2 \mathrm{~h}$ to enhance adhesion force between the precursor solutions and substrate $[15,16]$ and washed with DIW several times to remove impurities on the surface. Fig. S1 shows the SEM (JSM-6060, JEOL) images of (a) bared, (b) scrubbed, and (c) etched Ti surfaces. It was observed that many scratches formed on the Ti substrates after scrubbing by SIC paper and the surface was significantly changed to porous structure by chemical etching process.

Precursor mixture containing iridium and ruthenium with 1:1 molar ratio was prepared by mixing of $\mathrm{IrCl}_{3} \cdot 3 \mathrm{H}_{2} \mathrm{O}(99.8 \%$, Alfa aesar) and $\mathrm{RuCl}_{3} \cdot \mathrm{xH}_{2} \mathrm{O}$ (99.9\%, Alfa aesar) in different concentrations (100 and $500 \mathrm{mM}$ ) with 2-propanol ( $\geq 99.5 \%$, Sigma Aldrich) solution. An exact amount of homogeneous precursor mixtures was dropped onto the Ti substrate until forming thick layer and spread out precursor mixtures uniformly by centrifugal force at $1,000 \mathrm{rpm}$ using spin coater. The substrates coated by the precursor were dried at $80^{\circ} \mathrm{C}$ for $10 \mathrm{~min}$ to evaporate solvent (i.e., 2-propanol). The back side was also coated by following the procedure described above. Finally, the Ti substrates coated both sides by Ir and Ru precursors were calcinated at $450^{\circ} \mathrm{C}$ for $10 \mathrm{~min}$ in air furnace atmosphere. We repeated the procedure 4 times more for each $\mathrm{Ti} / \mathrm{Ir}-\mathrm{Ru}$ anode to obtain a desired thickness of oxide films.

\subsection{Surface and Electrochemical Characterization of Ti/Ir-Ru Anodes}

For analysis of surface characteristics of Ti/Ir-Ru anodes, we washed each $\mathrm{Ti} / \mathrm{Ir}-\mathrm{Ru}$ anode with DIW several times to remove the residual impurities and cut them to make the size of $5 \times 5 \mathrm{~mm}^{2}$. The surface morphology and elemental distribution of Ti/Ir-Ru anodes were identified by FESEM-EDX (SU8010_EX370, Hitachi). For FESEM-EDX analysis, the specimens were put on a carbon tape and coated by platinum for $30 \mathrm{~s}$. AFM (LabRAM HR800, Horiba Jobin-Yvon) was applied to characterize the topography of $\mathrm{Ti} / \mathrm{Ir}-\mathrm{Ru}$ anodes at high resolution $(\sim \mathrm{nm}$ scale). The mineral phase and oxidation state of elements on the surface of $\mathrm{Ti} / \mathrm{Ir}-\mathrm{Ru}$ anodes were analyzed with XRD (Smartlab, Rigaku) and XPS (K-alpha, Thermo VG Scientific) [17], respectively. Cyclic voltammograms for $\mathrm{Ti} / \mathrm{Ir}-\mathrm{Ru}$ anodes were recorded by using a SP-150 potentiostat (Bio-Logic Science Instruments). The experiments were performed in the range of -0.1-1.5 $\mathrm{V}$ in $0.5 \mathrm{M} \mathrm{H}_{2} \mathrm{SO}_{4}$ solution containing $1 \mathrm{~g} / \mathrm{L}$ of $\mathrm{Cu}$. The stainless steel, $\mathrm{Ag} / \mathrm{AgCl}$, and the $\mathrm{Ti} / \mathrm{Ir}-\mathrm{Ru}$ anodes were used as a counter, reference, and working electrode in the cell, respectively.

\subsection{Electrowinning of Copper}

A rectangular batch reactor $\left(90 \times 120 \times 170 \mathrm{~cm}^{3}\right)$ (Fig. S2) was used for the removal and recovery of $\mathrm{Cu}$ in synthetic wastewater in this study [18]. A commercial stainless steel (SUS 304) and $\mathrm{Ti} / \mathrm{Ir}-\mathrm{Ru}$ electrodes developed in this study were used as a cathode and anode $\left(10 \times 7 \times 0.04 \mathrm{~cm}^{3}\right)$, respectively. The distance between electrodes was designed to be $1 \mathrm{~cm}$. $1.5 \mathrm{~L}$ of synthetic wastewater prepared by $\mathrm{CuSO}_{4} \cdot 5 \mathrm{H}_{2} \mathrm{O}$ (99\%, Samchun) in $0.5 \mathrm{M} \mathrm{H}_{2} \mathrm{SO}_{4}$ solution was used for recovery of $\mathrm{Cu}$ by the electrowinning process. Two different $\mathrm{Cu}$ concentrations ( 1 and $10 \mathrm{~g} / \mathrm{L}$ ) were used to simulate highly concentrated industrial wastewater and leached liquor from metal sludge in acidic media.

All electrowinning experiments were carried out at constant imposed voltage (2.4 V) by using a DC Power Supply (EX30-60) in mixing condition at $200 \mathrm{rpm}$ at room temperature $\left(24 \pm 1.5^{\circ} \mathrm{C}\right)$. In order to monitor the removal kinetics of $\mathrm{Cu}$, we collected $4 \mathrm{~mL}$ of aqueous sample at each sampling time and analyzed the $\mathrm{Cu}$ concentration by inductively coupled plasma-optical emis- 
sion spectrometry (ICP-OES, Thermo). The amount of $\mathrm{Cu}$ deposited on the stainless steel cathode was also measured after finishing the experiments to compare with the concentration of $\mathrm{Cu}$ removed in aqueous phase.

\section{Results and Discussion}

\subsection{Morphological Characteristics of Ti/Ir-Ru Anodes}

Fig. 1 shows the SEM images of Ti/Ir-Ru anodes coated with 100 (Fig. 1 (a)) and $500 \mathrm{mM}$ (Fig. 1 (b)) precursor solutions. The scratches and porous structure on the surface of Ti substrates created during the pretreatment processes were not observed owing to formation of metal oxide film. It should be noted that each anode prepared by 100 and $500 \mathrm{mM}$ of precursor solutions displayed different surface morphology. We observed a distribution of needle shaped nanoparticles on the surface of Ti/Ir-Ru anode prepared by $100 \mathrm{mM}$ precursor (Fig. 1 (a-1)), which forms wave patterns on the $\mathrm{Ti}$ substrate. In contrast, a relatively uniformed flat area and cracked-mud structure was obtained from the Ti/Ir-Ru anode prepared at $500 \mathrm{mM}$ precursor (Fig. 1 (b-1)), which can be typically observed when the metal oxide films formed by the thermal decomposition method. The results indicate that an optimal precursor concentration should be considered during the development of $\mathrm{Ti} / \mathrm{Ir}-\mathrm{Ru}$ electrodes by the spin coating technique. The formation of cracks may form during the solvent evaporation and cooling process of the electrodes [19].

Fig. S3 shows the cross-sectional SEM images for Ti/Ir-Ru anodes prepared by 100 (Fig. S3(a)) and $500 \mathrm{mM}$ (Fig. S3(b)) of precursor solutions. For the sample of $100 \mathrm{mM}$, the boundary layer between metal oxide film and $\mathrm{Ti}$ substrate was not clearly observed owing to the insufficient amount of metal loading on the surface of Ti substrate. In contrast, we observed a clear formation of metal oxide film for the sample of $500 \mathrm{mM}$ with an approximate thickness of $3 \mu \mathrm{m}$. Normally, the thickness of oxide film higher than $2 \mu \mathrm{m}$ has been considered as an appropriate electrode [19], indicating that the Ir-Ru precursor solution higher than $100 \mathrm{mM}$ may be needed to create a proper metal oxide film on the surface of $\mathrm{Ti}$ substrate.

The presence of main elements (i.e., Ti, Ir, and $\mathrm{Ru}$ ) on the surface of $\mathrm{Ti} / \mathrm{Ir}-\mathrm{Ru}$ anodes was determined by EDX mapping as shown in Fig. 2. We observed a large amount of $\mathrm{Ti}$ on the surface of $\mathrm{Ti} / \mathrm{Ir}-\mathrm{Ru}$ anode prepared by $100 \mathrm{mM}$ precursor, resulting in a relatively small amount of Ir and Ru with a poorly distributed condition (Fig. 2(a)), while the Ti/Ir-Ru anode prepared by 500
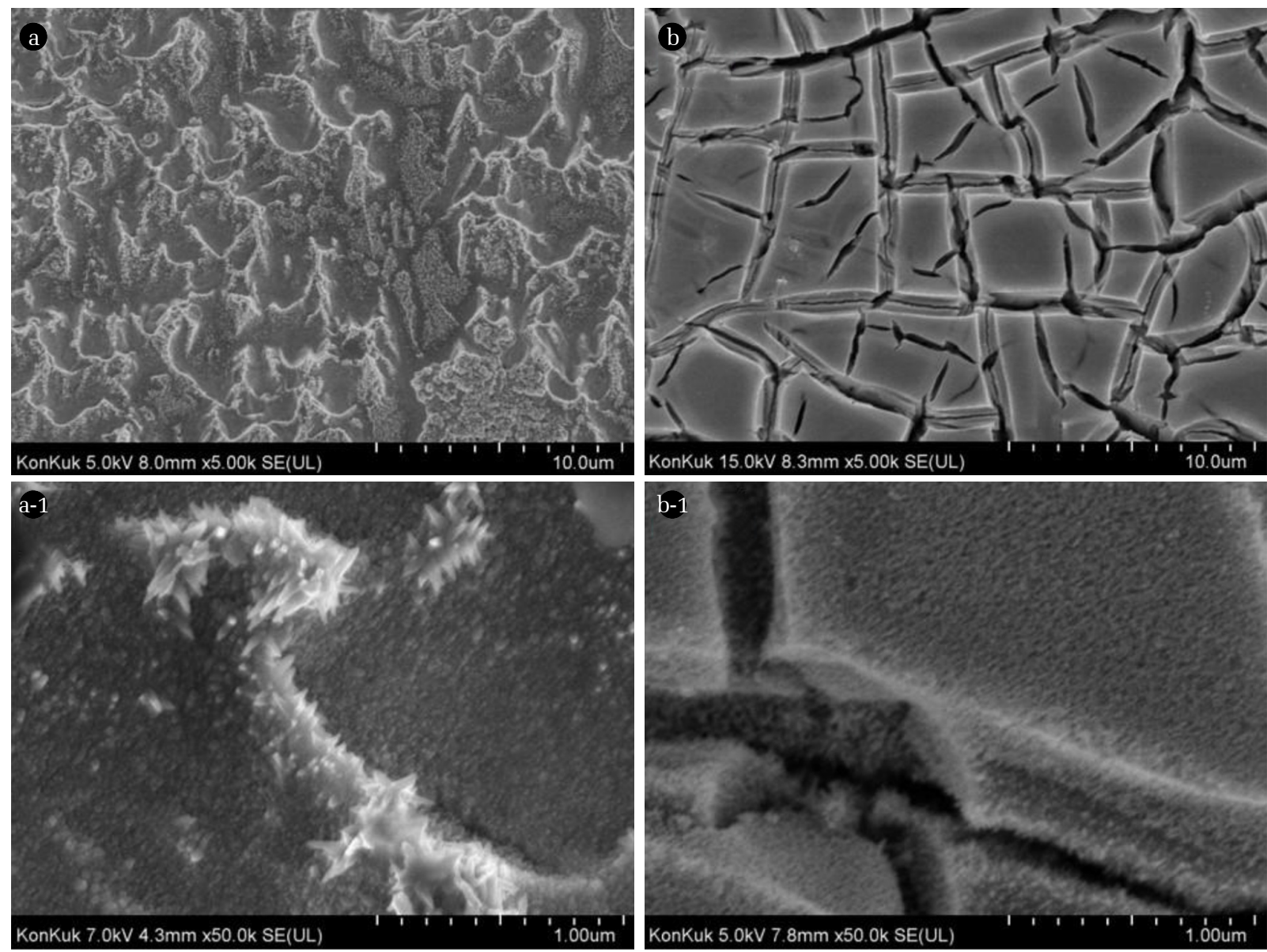

Fig. 1. SEM images of the Ti/lr-Ru anodes coated with (a) 100 and (b) $500 \mathrm{mM}$ precursor solutions and their enlarged images (a-1 and b-1). 


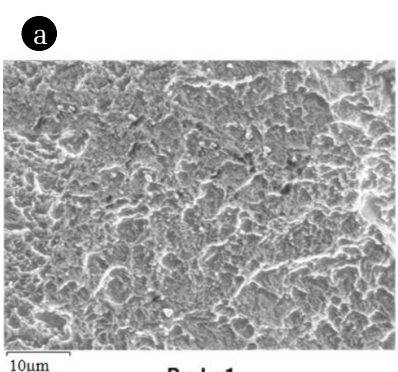

$10 \mu \mathrm{m}$

Ru $L \alpha 1$

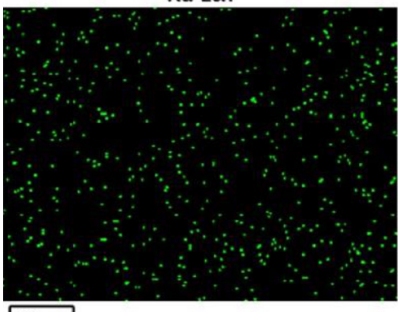

$10 \mu \mathrm{m}$

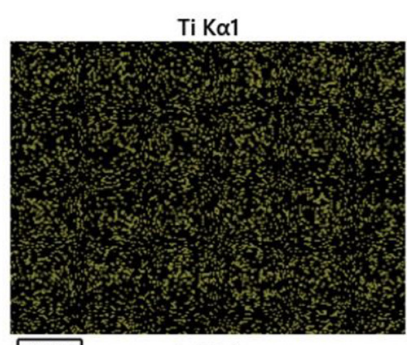

Ir $\mathrm{M} \alpha 1$

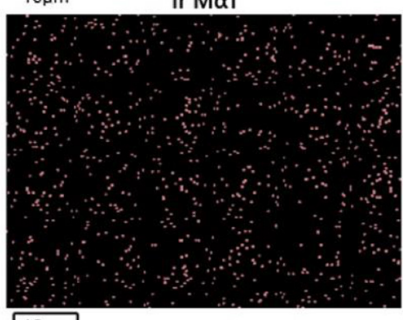

(b)

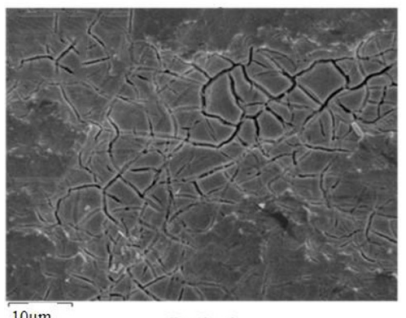

$10 \mu \mathrm{m}$

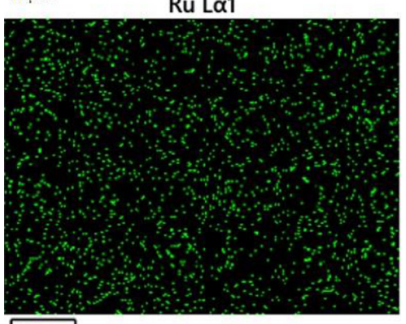

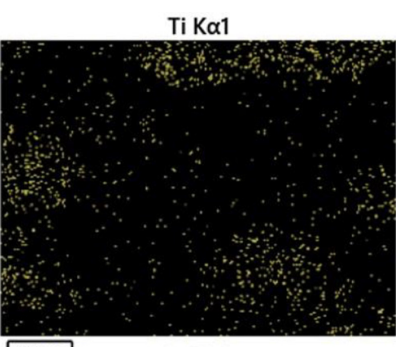

10um $\quad$ Ir $M \alpha 1$

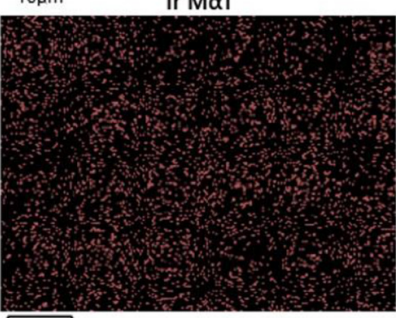

Fig. 2. FE-SEM images and corresponding results of EDX mapping for the Ti/lr-Ru anodes coated with (a) 100 and (b) 500 mM precursor solutions.
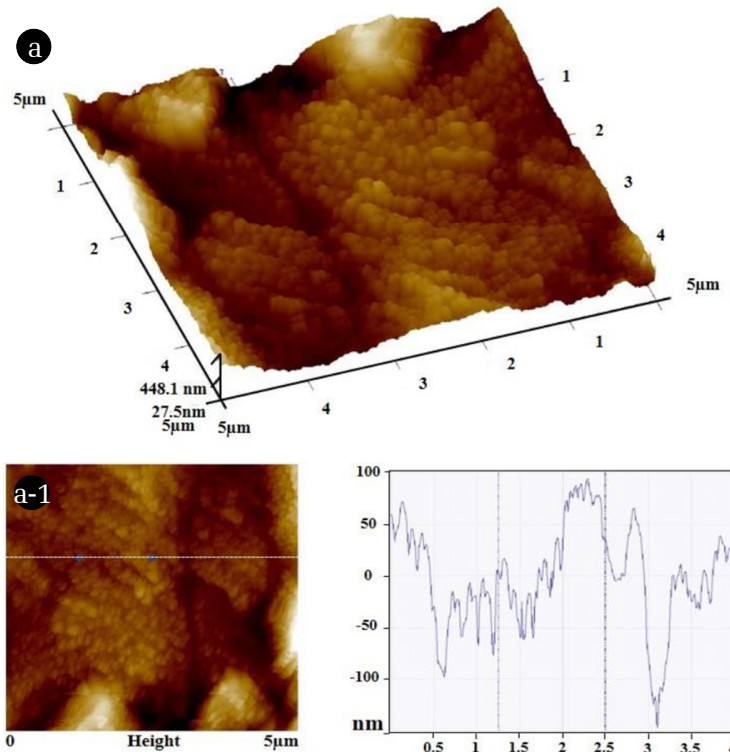

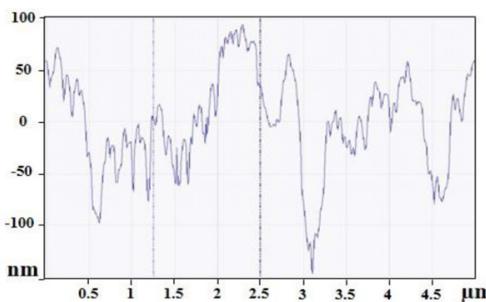

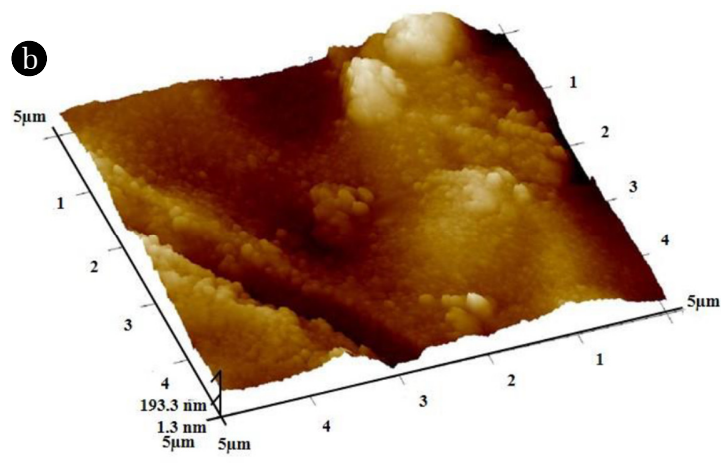
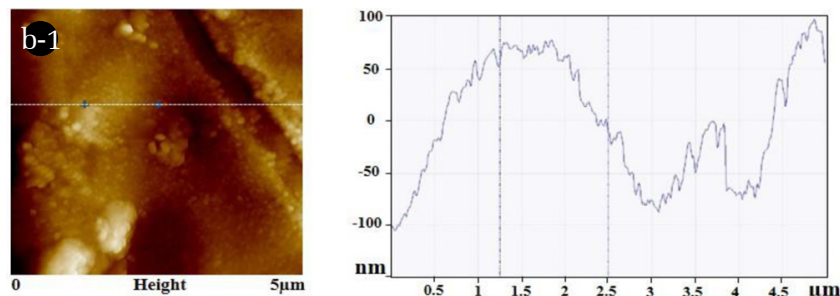

Fig. 3. 3D AFM images of the Ti/lr-Ru anodes coated with (a) 100 and (b) $500 \mathrm{mM}$ precursor solutions and their 2D scanned images with topography information (a-1 and b-1).

$\mathrm{mM}$ precursor revealed a relatively small amount of Ti with large amount and well distributed Ir and Ru on the surface. In particular, almost no Ti was detected in the areas of cracked-mud, indicating that these areas possess a thick Ir-Ru oxide layer as shown in the SEM images. AFM images for the sample of $100 \mathrm{mM}$ displayed that lateral fluctuations of surface features can be detected in almost every $250 \mathrm{~nm}$ distance with 30-200 nm of topography deviation (Fig. 3(a) and (a-1)). In comparison, we did not observe a significant change in topography for the sample of $500 \mathrm{mM}$ (Fig. 3(b) and 3(b-1)), which show a relatively flat surface than that of $100 \mathrm{mM}$ sample as concluded from the SEM results. All morphological information from SEM-EDX and AFM revealed that the $\mathrm{Ti} / \mathrm{Ir}-\mathrm{Ru}$ electrode prepared by $500 \mathrm{mM}$ precursor solution may have a high potential to be used for efficient anode of electrowinning process rather than that of $100 \mathrm{mM}$.

\subsection{X-ray Based Analysis (XRD and XPS) for Ti/lr-Ru Anodes}

Crystallinity and mineral phase on the surface of each Ti/Ir-Ru were investigated by XRD in the range of $10-80^{\circ} 2 \theta$ (Fig. S4). We observed the presence of several peaks corresponding to $\mathrm{IrO}_{2}$, $\mathrm{RuO}_{2}, \mathrm{TiO}_{2}$, and $\mathrm{Ti}$ on the surface of both Ti/Ir-Ru anodes. The peaks for both metal oxides (i.e., Ir and $\mathrm{Ru}$ ) were observed in the identical $2 \theta$ values with rutile type of $\mathrm{TiO}_{2}$ because the ionic radii of $\mathrm{Ru}^{4+}, \mathrm{Ir}^{4+}$, and $\mathrm{Ti}^{4+}$ are almost same as 0.076, 0.077 and 
$0.075 \mathrm{~nm}$, respectively [12]. It is noteworthy that the peak intensity for $\mathrm{IrO}_{2}$ and $\mathrm{RuO}_{2}$ increased as concentration of precursor solution increased from 100 to $500 \mathrm{mM}$, leading to the decrease in peak intensity of Ti. The results was in good agreement with what we obtained from EDX analysis, implying that the Ir-Ru metal oxide films covered well on the surface of Ti substrate [12].

The XPS analysis was also conducted to investigate the oxidation states of Ir and $\mathrm{Ru}$ on the surface of Ti/Ir-Ru anode prepared by $500 \mathrm{mM}$ precursor solution (Fig. S5). The narrow region spectra for $\mathrm{Ru}\left(3 \mathrm{p}_{5 / 2}\right)$ (Fig. S5(a)) and Ir $\left(4 \mathrm{f}_{7 / 2}\right)$ revealed the presence of zerovalent metals $(\mathrm{Ru}(0)$ and $\operatorname{Ir}(0))$ and oxides forms $\left(\mathrm{RuO}_{2}\right.$ and $\mathrm{IrO}_{2}$ ), but the most dominant form was each metal oxides which was corresponding to the results of XRD.

\subsection{Cyclic Voltammetry Measurement for Ti/lr-Ru Anodes}

Cyclic voltammetry experiments were performed to investigate the electrochemical characterization of each Ti/Ir-Ru anode (Fig. S6). A cathodic peak was observed at approximately $-0.1 \mathrm{~V}$ potential due to hydrogen evolution (Eq. (1)) and $\mathrm{Cu}$ (Eq. (2)) deposition, while the anodic peak was observed at approximately $1.5 \mathrm{~V}$ potential owing to oxygen evolution (Eq. (3)).

$$
\begin{array}{cc}
\text { Cathode: } 2 \mathrm{H}^{+}+2 \mathrm{e}^{-}=\mathrm{H}_{2} & \mathrm{E}^{0}=+0.00 \mathrm{~V} \\
\text { Cathode: } \mathrm{Cu}^{2+}+2 \mathrm{e}^{-}=\mathrm{Cu} & \mathrm{E}^{0}=+0.34 \mathrm{~V}
\end{array}
$$

$$
\text { Anode: } \mathrm{H}_{2} \mathrm{O}=1 / 2 \mathrm{O}_{2}+2 \mathrm{H}^{+}+2 \mathrm{e}^{-} \quad \mathrm{E}^{0}=-1.23 \mathrm{~V}
$$

In addition, slight peaks were detected at 0.5 and $0.6 \mathrm{~V}$ for 100 and $500 \mathrm{mM}$ coated electrodes, respectively. We obtained slightly irreversible peaks during the cyclic voltammetry experiment, which is attributed to the transition of $\mathrm{Ru}$ and Ir from (III) to (IV) species [20, 21]. Overall increase in current density was observed in the sample of $500 \mathrm{mM}$, indicating that the 500 $\mathrm{mM}$ coated $\mathrm{Ti} / \mathrm{Ir}-\mathrm{Ru}$ anode possess larger electrochemically active surface area than that of $100 \mathrm{mM}$ sample.
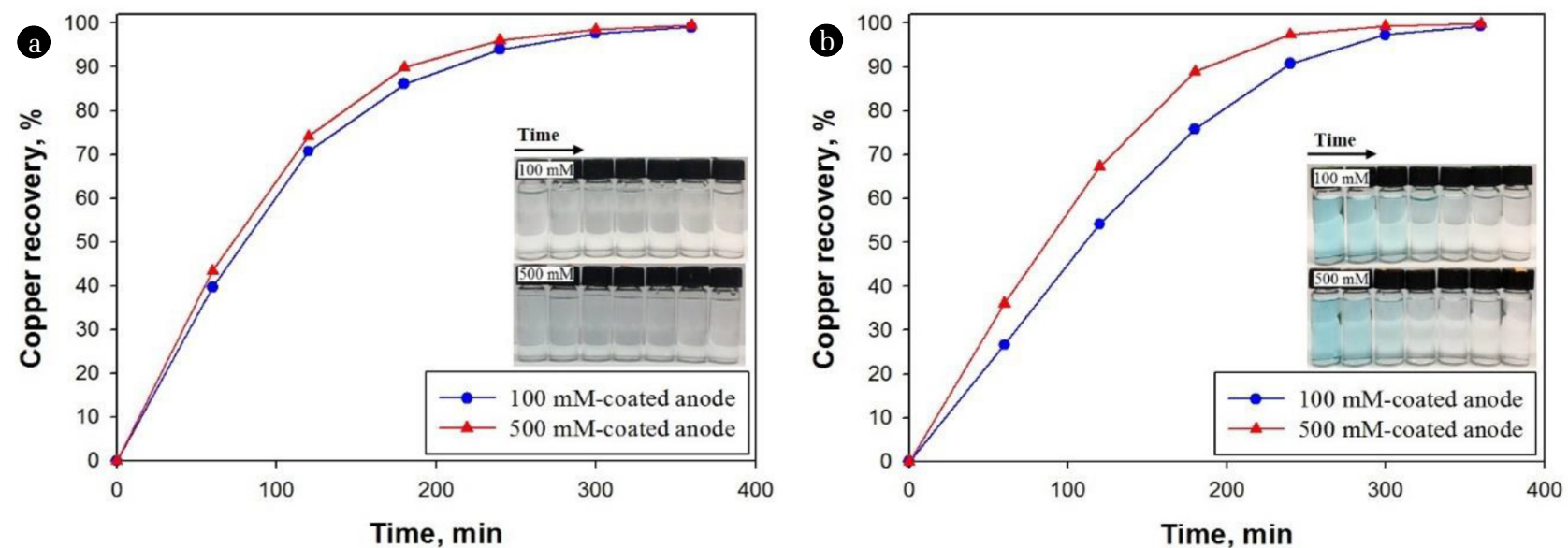

Fig. 4. The efficiency of $\mathrm{Cu}$ removal during electrowinning process using a stainless steel cathode and Ti/lr-Ru anodes in the (a) $1 \mathrm{~g} / \mathrm{L}$ and (b) $10 \mathrm{~g} / \mathrm{L} \mathrm{Cu}$ solutions.

\subsection{Electrowinning Process Using Ti/lr-Ru Anodes for Recovery of $\mathrm{Cu}$}

Fig. 4 shows the removal efficiencies of $\mathrm{Cu}$ ((a) 1 and (b) 10 $\mathrm{g} / \mathrm{L})$ by electrowinning process working with different $\mathrm{Ti} / \mathrm{Ir}-\mathrm{Ru}$ anodes and a stainless steel cathode in $0.5 \mathrm{M} \mathrm{H}_{2} \mathrm{SO}_{4}$ solution. During the electrowinning of $\mathrm{Cu}$, it may be expected the redox reactions at each cathode (Eq. (1) and (2), net cathodic reaction: $\mathrm{Cu}^{2+}+2 \mathrm{H}^{+}+4 \mathrm{e}^{-}=\mathrm{Cu}(0)+\mathrm{H}_{2}$ ) and anode (Eq. (3)). All electrowinning experiments were carried out at a constant cell voltage $(2.4 \mathrm{~V})$, because the voltage lower than $2.4 \mathrm{~V}$ may significantly oxidize metallic $\mathrm{Cu}(0)$ to $\mathrm{Cu}_{2} \mathrm{O}$ [22]. For the case of $1 \mathrm{~g} / \mathrm{L} \mathrm{Cu}$, a complete $\mathrm{Cu}$ removal was obtained within $6 \mathrm{~h}$ reaction in the experiments using both Ti/Ir-Ru anodes and their removal kinetics were almost similar due probably to a relatively low initial concentration of $\mathrm{Cu}$ with high enough potential. Compared to that of $100 \mathrm{mM}$ case, we observed the enhanced $\mathrm{Cu}$ removal for the case of $10 \mathrm{~g} / \mathrm{L} \mathrm{Cu}$ by using the $500 \mathrm{mM}$ coated Ti/Ir-Ru anode, showing the complete removal within $5 \mathrm{~h}$ reaction. The differences in $\mathrm{Cu}$ concentration from 0 to $3 \mathrm{~h}$ reaction were varied in the level of thousand $\mathrm{mg} / \mathrm{L}$ between both cases, which is considered as a significant enhancement in $500 \mathrm{mM}$ case. In addition, the initial blue color of synthetic $\mathrm{Cu}$ wastewater changed to be transparent after finishing the electrowinning (Fig. 4 (a) and (b) insets), indicating the complete removal of aqueous $\mathrm{Cu}$. The results indicate that the initial concentration of $\mathrm{Cu}$ can influence the total removal efficiency significantly [23] and Ti/Ir-Ru electrode can be used as an anode for efficient removal of highly concentrated $\mathrm{Cu}$ in the wastewater owing to the enhanced physical and electrochemical properties as shown above.

The removal kinetics of $\mathrm{Cu}$ in this study can be described as two distinct stages from initial time to $2 \mathrm{~h}$ (Fig. 5(a)) and after 2 h (Fig. 5(b)), which were followed by zero-order (Eq. (4)) and first-order kinetics (Eq. (5)), respectively [22].

$$
\begin{gathered}
{\left[\mathrm{Cu}^{2+}\right]_{\mathrm{t}}=\left[\mathrm{Cu}^{2+}\right]_{\mathrm{i}}-\mathrm{k}_{0} \mathrm{t}} \\
\ln \left(\left[\mathrm{Cu}^{2+}\right]_{\mathrm{t}}\right)=\left[\ln \left(\left[\mathrm{Cu}^{2+}\right]_{\mathrm{t}^{*}}\right)+\mathrm{k}_{1} \mathrm{t}^{*}\right]-\mathrm{k}_{1} \mathrm{t}
\end{gathered}
$$


Table 1. The $k_{0}$ and $k_{1}$ Values for Electrowinning Experiments

\begin{tabular}{|c|c|c|c|c|}
\hline \multirow{2}{*}{ Copper concentration in synthetic solution } & \multicolumn{2}{|c|}{$\mathbf{k}_{\mathbf{0}}(\mathrm{mg} / \mathrm{L} \cdot \mathbf{m i n})$} & \multicolumn{2}{|c|}{$k_{1}\left(\min ^{-1}\right)$} \\
\hline & $100 \mathrm{mM}$ & $500 \mathrm{mM}$ & $100 \mathrm{mM}$ & $500 \mathrm{mM}$ \\
\hline $1 \mathrm{~g} \mathrm{Cu} / \mathrm{L}$ solution & 5.78 & 6.17 & $1.49 \mathrm{e}^{-2}$ & $1.69 \mathrm{e}^{-2}$ \\
\hline $10 \mathrm{~g} \mathrm{Cu} / \mathrm{L}$ solution & 42.65 & 57.56 & $2.00 \mathrm{e}^{-2}$ & $2.44 \mathrm{e}^{-2}$ \\
\hline
\end{tabular}
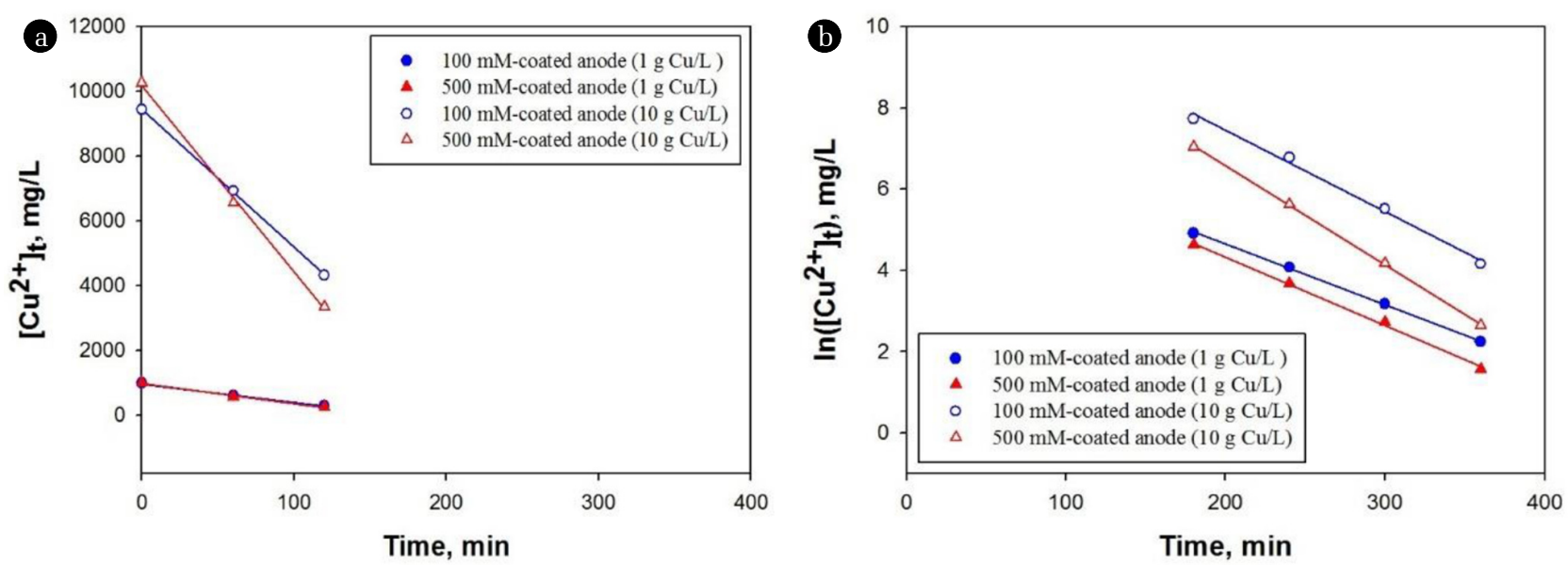

Fig. 5. The linear plots of (a) zero- and (b) first-order kinetics of $\mathrm{Cu}$ recovery by electrowinning process.
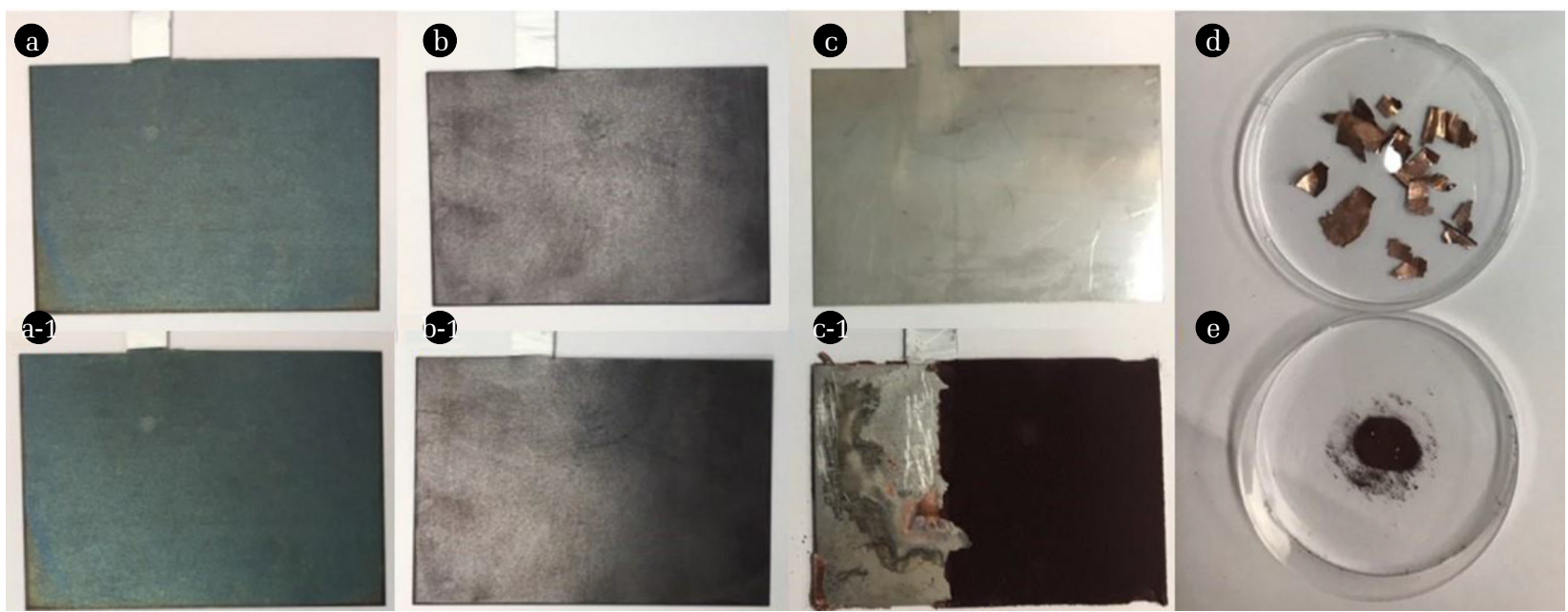

Fig. 6. The images of Ti/lr-Ru anodes coated by $100 \mathrm{mM}$ precursor (a) before and (a-1) after the electrowinning of Cu. (b), (b-1), (c), and (c-1) describe Ti/lr-Ru anodes coated by $500 \mathrm{mM}$ precursor and stainless steel cathodes before and after the electrowinning of $\mathrm{Cu}$, respectively. The recovered $\mathrm{Cu}$ after the electrowinning as a (d) $\mathrm{Cu}(0)$ foil and (e) $\mathrm{CuO}_{2}$ powder.

where $\left[\mathrm{Cu}^{2+}\right]_{\mathrm{t}}$ is the $\mathrm{Cu}$ concentration at time $\mathrm{t},\left[\mathrm{Cu}^{2+}\right]_{\mathrm{i}}$ is the initial $\mathrm{Cu}$ concentration, $\mathrm{k}_{0}$ is the zero-order rate constant, and $\mathrm{k}_{1}$ is the first-order rate constant, respectively. A good linearity for all kinetic analysis was obtained in this study, which is in agreement with previous study [22]. The change in kinetic orders may be due to the requirement of induction time for the $\mathrm{Cu}$ reduction at initial period [24]. After finishing the induction period, the removal kinetics was followed by first-order, which highlights the importance of aqueous $\mathrm{Cu}$ concentration after $2 \mathrm{~h}$ reaction. Table 1 shows the $k_{0}$ and $k_{1}$ values for each experiment, showing that all the $\mathrm{k}$ values for $500 \mathrm{mM}$ coated $\mathrm{Ti} / \mathrm{Ir}-\mathrm{Ru}$ anode were higher than that of $100 \mathrm{mM}$ case.

Fig. 6 shows the images of Ti/Ir-Ru anodes before and after the $\mathrm{Cu}$ removal $(10 \mathrm{~g} / \mathrm{L})$ in the synthetic wastewater. Almost no change was observed from the initial Ti/Ir-Ru anodes (a: 100 $\mathrm{mM}$ and b: $500 \mathrm{mM}$ ) after the electrowinning (a-1: $100 \mathrm{mM}$ and b-1: $500 \mathrm{mM}$ ), while a significant change was observed in the stainless steel cathode, resulting in the attachment of dark powders on the surface (Fig. 6(c-1)) after the electrowinning comparable to that of the initial Ti/Ir-Ru anode (Fig. 6(c)). The formation of dark powder may be attributed the oxidation of inner metallic $\mathrm{Cu}(0)$ to $\mathrm{Cu}_{2} \mathrm{O}$ through the direct reaction by oxygens during 
the electrowinning process. The oxygens could be formed on the surface of anode and transferred to the cathode owing to an aggressive stirring in this study [22]. Indeed, we observed the presence of $\mathrm{Cu}(0)$ foil (Fig. 6(d)) inside of $\mathrm{CuO}_{2}$ powders (Fig. 6(e)). In addition, weight of $\mathrm{Cu}$ recovered by electrowinning process was measured after the experiments, confirming the recovery efficiency higher than $100 \%$ in all the experiments (Table $\mathrm{S} 1)$. The $\mathrm{Cu}$ weight higher than we injected into the reactor may be induced by the presence of $\mathrm{CuO}_{2}$ powders, which increase the weight of $\mathrm{Cu}$ in total. The results showed that the highly concentrated $\mathrm{Cu}$ could be effectively removed and recovered by electrowinning process working with a well fabricated $\mathrm{Ti} / \mathrm{Ir}-\mathrm{Ru}$ anode by the spin coating technique.

\section{Conclusions}

In this study, the spin coating technique was successfully employed to fabricate Ti/Ir-Ru electrodes for different concentrations of precursor that can be used for removal and recovery of valuable metals in wastewater. The results from various surface analysis showed that $\mathrm{Ti} / \mathrm{Ir}-\mathrm{Ru}$ anode surface prepared by $500 \mathrm{mM}$ precursor solution possessed a cracked-mud structure and the metal oxide films of Ir and Ru were well deposited on the Ti substrate. Cyclic voltammetry revealed an overall increase in current density in the sample of $500 \mathrm{mM}$, implying that it can be favored for the electrowinning process. Indeed, we observed the enhanced $\mathrm{Cu}$ removal by using the Ti/Ir-Ru anode prepared by $500 \mathrm{mM}$ precursor solution in the case of $10 \mathrm{~g} / \mathrm{L}$ of $\mathrm{Cu}$. Finally, the amount of $\mathrm{Cu}$ deposited on the cathode was easily recovered by scrubbing the electrode surface. The results obtained from this study can provide the fundamental knowledge of surface characteristics of Ti/Ir-Ru electrode fabricated by spin coating technique and its feasibility to be used as an effective anode for removal and recovery of heavy metals by the electrowinning process.

\section{Acknowledgments}

This subject is supported by Korea Ministry of Environment (MOE) as "Technologies for the Risk Assessment and Management Program (2017000140006)" and the Korea Institute of Energy Technology Evaluation and Planning (KETEP) and the Ministry of Trade, Industry and Energy (MOTIE, 20174010201490).

\section{References}

1. Kadirvelu K, Thamaraiselvi K, Namasivayam C. Removal of heavy metals from industrial wastewaters by adsorption onto activated carbon prepared from an agricultural solid waste. Bioresour. Technol. 2001;76:63-65.

2. Varma GV, Misra AK. Equilibrium and kinetic studies on the adsorption of copper onto carica papaya leaf powder. Membr. Water Treat. 2016;7:403-416.

3. Sharma RK, Agrawal M. Biological effects of heavy metals:
An overview. J. Environ. Biol. 2005;26:301-313.

4. Zhang Y, Tang Q, Chen S, Gu F, Li Z. Heavy metal adsorption of a novel membrane material derived from senescent leaves: Kinetics, equilibrium and thermodynamic studies. Membr. Water Treat. 2018;9:95-104.

5. Li PP, Peng CS, Li FM, Song SX, Juan AO. Copper and nickel recovery from electroplating sludge by the process of acid-leaching and electro-depositing. Int. J. Environ. Res. 2011;5:797-804.

6. Agrawal A, Kumari S, Sahu KK. Iron and copper recovery/removal from industrial wastes: A review. Ind. Eng. Chem. Res. 2009;48:6145-6161.

7. Msindo ZS, Sibanda V, Potgieter JH. Electrochemical and physical characterisation of lead-based anodes in comparison to Ti-(70\%) $\mathrm{IrO}_{2} /(30 \%) \mathrm{Ta}_{2} \mathrm{O}_{5}$ dimensionally stable anodes for use in copper electrowinning. J. Appl. Electrochem. 2010;40: 691-699.

8. Mussy JPG, Macpherson JV, Delplancke JL. Characterisation and behaviour of $\mathrm{Ti} / \mathrm{TiO}_{2} /$ noble metal anodes. Electrochim. Acta 2003;48:1131-1141.

9. Zhang W, Ghali E, Houlachi G. Review of oxide coated catalytic titanium anodes performance for metal electrowinning. Hydrometallurgy 2017;169:456-467.

10. Audichon T, Mayousse E, Morisset S, et al. Electroactivity of $\mathrm{RuO}_{2}-\mathrm{IrO}_{2}$ mixed nanocatalysts toward the oxygen evolution reaction in a water electrolyzer supplied by a solar profile. Int. J. Hydrogen Energ. 2014;39:16785-16796.

11. Hu JM, Meng HM, Zhang JQ, Cao CN. Degradation mechanism of long service life $\mathrm{Ti} / \mathrm{IrO}_{2}-\mathrm{Ta}_{2} \mathrm{O}_{5}$ oxide anodes in sulphuric acid. Corros. Sci. 2002;44:1655-1668.

12. Moradi F, Dehghanian C. Addition of $\mathrm{IrO}_{2}$ to $\mathrm{RuO}_{2}+\mathrm{TiO}_{2}$ coated anodes and its effect on electrochemical performance of anodes in acid media. Prog. Nat. Sci. Mater. 2014;24:134-141.

13. Hummelgård C, Gustavsson J, Cornell A, Olin H, Bäckström J. Spin coated titanium-ruthenium oxide thin films. Thin Solid Films 2013;536:74-80.

14. Fierro S, Comninellis C. Kinetic study of formic acid oxidation on $\mathrm{Ti} / \mathrm{IrO}_{2}$ electrodes prepared using the spin coating deposition technique. Electrochim. Acta 2010;55:7067-7073.

15. Yan Z, Zhao Y, Zhang Z, et al. A study on the performance of $\mathrm{IrO}_{2}-\mathrm{Ta}_{2} \mathrm{O}_{5}$ coated anodes with surface treated Ti substrates. Electrochim. Acta 2015;157:345-350.

16. Maharana D, Xu Z, Niu J, Rao NN. Electrochemical oxidation of 2,4,5-trichlorophenoxyacetic acid by metal-oxide-coated $\mathrm{Ti}$ electrodes. Chemosphere 2015;136:145-152.

17. Park J, Bae S. Formation of Fe nanoparticles on water-washed coal fly ash for enhanced reduction of p-nitrophenol. Chemosphere 2018;202:733-741.

18. Park KY, Cha HY, Chantrasakdakul P, Lee K, Kweon JH, Bae S. Removal of nitrate by electrodialysis: Effect of operation parameters. Membr. Water Treat. 2017;8:201-210.

19. Berenguer R, Quijada C, Morallón E. Electrochemical characterization of $\mathrm{SnO}_{2}$ electrodes doped with $\mathrm{Ru}$ and Pt. Electrochim. Acta 2009;54:5230-5238.

20. Fóti G, Mousty C, Reid V, Comninellis C. Characterization of DSA type electrodes prepared by rapid thermal decomposition of the metal precursor. Electrochim. Acta 
1998;44:813-818.

21. Kötz R, Stucki S. Stabilization of $\mathrm{RuO}_{2}$ by $\mathrm{IrO}_{2}$ for anodic oxygen evolution in acid media. Electrochim. Acta 1986;31: 1311-1316.

22. Giannopoulou I, Panias D. Copper and nickel recovery from acidic polymetallic aqueous solutions. Miner. Eng. 2007;20: 753-760.
23. Khouraibchia Y, Moats MS. Evaluation of the effect of copper electrowinning parameters on current efficiency and energy consumption using surface response methodology. ECS Trans. 2010;28:295-306.

24. Viswanath SG, George S. Electrowinning of copper powder from sulphate solution in presence of glycerol and sulphuric acid. Indian J. Chem. Technol. 2011;18:37-44. 